Geopolítica(s) Revista de estudios sobre espacio y poder ISSN: 2172-3958

https://dx.doi.org/10.5209/geop.63321

\title{
Una mirada territorial de la lucha armada: las FARC-EP y Sendero Luminoso $^{1}$
}

Jerónimo Ríos Sierra ${ }^{2}$

Recibido: 3 de abril de 2019/ Aceptado: 2 de marzo de 2020

Resumen. El siguiente artículo indaga en la relación territorial que tuvieron los dos grupos armados más importantes de la región andina en el pasado siglo XX: las Fuerzas Armadas Revolucionarias de Colombia - Ejército del Pueblo (FARC-EP) y Partido Comunista del Perú - Sendero Luminoso (PCP$\mathrm{SL}$ ). Partiendo de un marco teórico que vincula el origen y subsistencia de los grupos insurgentes a condiciones de inaccesibilidad y de disposición de recursos, se analiza desde una perspectiva comparada, la secuencia espacio-temporal de la aparición, desarrollo y auge y debilitamiento de cada uno de estos dos grupos con una lógica periferia-centro-periferia. Esto es, un surgimiento en dos contextos periféricos como son Marquetalia y Ayacucho, una búsqueda de la centralidad, producto de una acumulación de fuerzas notable, y tras la respuesta beligerante del Estado en último término, unido a otros factores, un retorno a la condición periférica.

Palabras clave: centro-periferia; territorio; FARC-EP; lucha armada; Sendero Luminoso.

\section{[en] A Territorial View of the Armed Struggle: The FARC-EP and the Shining Path}

\begin{abstract}
The following article explores the territorial relationship between the two most important armed groups in the Andean region in the last century: The Revolutionary Armed Forces of Colombia - People's Army (FARC-EP) and the Communist Party of Peru - Shining Path (PCP-SL). Starting from a theoretical framework that links the emergence and subsistence of the insurgent groups to conditions of inaccessibility and resource disposition, the article carries out a comparative analysis of the spatial-temporal sequence "emergence, development, climax and decline" developed by the insurgent groups. The article argues that such trajectories unfold according to a logic periphery-centreperiphery. Having emerged in two peripheral contexts such as Marquetalia and Ayacucho, the insurgent groups stand out for their search for centrality as a result of a remarkable accumulation of forces which, followed by a belligerent State response and the impact of other factors, urges the return to the peripheral condition.
\end{abstract}

Keywords: centre-periphery; territory; FARC-EP; armed struggle; Shining Path.

\footnotetext{
1 Este artículo es producto del proyecto de investigación 2018-T2/SOC-10508.

2 Investigador postdoctoral en la Facultad de Ciencias Políticas y Sociología de la Universidad Complutense de Madrid, como beneficiario de las Ayudas de Atracción del Talento Investigador que cofinancia la Comunidad de Madrid (2018).

E-mail: jeronimo.rios@ucm.es
} 


\section{[pt] Um olhar territorial da luta armada: as FARC-EP e o Sendero Luminoso}

Resumo. O artigo a seguir explora a relação territorial entre os dois grupos armados mais importantes da região andina no século XX: as Forças Armadas Revolucionárias da Colômbia - Exército Popular (FARC-EP) e Partido Comunista do Peru - Sendero Luminoso (PCP-SL). Com base em uma revisão teórica que vincula o surgimento e subsistência dos grupos insurgentes a condições de inacessibilidade e disposição de recursos, uma seqüência espaço-temporal do aparecimento, desenvolvimento e explosão e enfraquecimento de cada um deles é analisada a partir de uma perspetiva comparativa. Isto é, uma emergência em dois contextos periféricos, como Marquetalia e Ayacucho, uma busca de centralidade, produto de uma notável acumulação de forças, e após a resposta beligerante do Estado em último recurso, juntamente com outros fatores, um retorno à condição periférica.

Palavras-chave: centro-periferia; território; FARC-EP; luta armada; Sendero Luminoso.

Sumario. Introducción. 1. Marco teórico y estado del arte. 2. Metodología. 3. Origen: fundamentos ideológicos e impronta periférica. 4. Desarrollo de la lucha armada: la búsqueda de la centralidad. 5. Decadencia y retorno a la periferia. Conclusiones. Referencias.

Cómo citar: Ríos Sierra, J. (2020). Una mirada territorial de la lucha armada: las FARC-EP y Sendero Luminoso. Geopolítica(s). Revista de estudios sobre espacio y poder, 11(1), 119-143.

\section{Introducción}

El siguiente trabajo tiene como propósito reflexionar sobre las dinámicas territoriales de la violencia desarrolladas por las dos guerrillas ${ }^{3}$ sudamericanas más influyentes de la segunda mitad del siglo XX en el continente sudamericano: el Partido Comunista del Perú-Sendero Luminoso (PCP-SL) ${ }^{4}$ y las Fuerzas Armadas Revolucionarias de Colombia - Ejército del Pueblo (FARC-EP) ${ }^{5}$. La selección de estos dos grupos armados no resulta casual. De un lado, son dos actores armados de impronta rural que surgen en escenarios recónditos, olvidados por la historia, tal y como sucede con Ayacucho en Perú o con la extinta "república independiente" de Marquetalia $^{6}$ en Colombia ${ }^{7}$. A tal efecto, ponen en valor categorías subalternas, invisibilizadas, como el campesino en el caso de Colombia (Pécaut, 2006) y el campesino e indio en el caso de Perú $^{8}$ (Degregori, 2011).

3 El término guerrilla, dentro de los elementos que la definen (Rey, 2008), podría ser un tanto problemática para el caso de Sendero Luminoso, pues en muchas ocasiones se asemejó más a un grupo terrorista que a una guerrilla stricto sensu.

4 Tal y como se verá con posterioridad, las siglas PCP-SL aparecen en 1970. Desde 1964 el PCP va experimentando varias escisiones, algunas de ellas son Bandera Roja (1964), Unidad (1964), PCP-ML (1968), Patria Roja (1969) o PCP-SL (1970) (Letts, 1981).

5 El término Ejército del Pueblo (EP) sería incorporado a las siglas FARC a partir de 1982, resultado de los compromisos adquiridos en su VII Conferencia Guerrillera.

6 En la actualidad, Marquetalia se ubicaría en el municipio de Planadas, al sur del departamento de Tolima.

7 El término "república independiente" surge a mediados del siglo XX en Colombia para hacer referencia a pequeños enclaves de disputa de impronta rural e influencia comunista que desafían la autoridad del Estado (Pizarro, 2011).

8 Sea como fuere, Sendero Luminoso fue algo más que complejo que simples campesinos, mayormente quechua-hablantes, levantados en armas. Tal y como han propuesto Portocarrero y Oliart (1989) o Degregori (1990), el maoísmo del PCP-Bandera Roja —y después PCP-Patria Roja-, que tuvo sus orígenes en franjas provincianas y universitarias del viejo PCP, con marcada presencia de maestros y estudiantes de universidades públicas, y con una relativa influencia en el campesinado que irá menguando con los años, tiene un claro lide- 
Asimismo, ambos grupos se desarrollan a lo largo de la década de los sesenta y entre los ochenta (PCP-SL) y los noventa (FARC-EP) llegaron a superar los 10.000 efectivos y otros tantos milicianos, de manera tal que pudieron abandonar sus orígenes periféricos para buscar un espacio de centralidad en el que la lucha armada sirviese de fuerza motriz para la consecución del poder político y la derrota del Estado. De hecho, gracias a una innegable capacidad de lucha y movilización de recursos - provenientes de secuestro, extorsión y negocio cocalero- en algún momento llegaron a poner en jaque a la institucionalidad peruana y colombiana. Sin embargo, dicha búsqueda de la centralidad en ambos casos fracasa.

Además, FARC-EP y PCP-SL son marcadamente diferentes en relación a otros grupos urbanos como Montoneros, Tupamaros o el Movimiento de Izquierda Revolucionaria, que operaron en el Cono Sur. Igualmente, su capacidad de disputa frente al Estado es la más notoria, respecto de grupos secundarios de Colombia, como el Ejército de Liberación Nacional (ELN) o el Movimiento 19 de Abril (M19), y de Perú, como el Movimiento Revolucionario Túpac Amaru (MRTA). Su persistencia en el tiempo es la única que trasciende notablemente, junto al ELN, al fin de la Guerra Fría. Además, FARC-EP y PCP-SL se desarrollan en escenarios de disputa particularmente amplios y diferenciados, lo que no sucede en los casos de las insurgencias, por ejemplo, centroamericanas, del Frente Sandinista de Liberación Nacional (Nicaragua), Frente Farabundo Martí para la Liberación Nacional (El Salvador) y la Unidad Revolucionaria Nacional Guatemalteca (Guatemala).

Si bien existen acontecimientos — como el atentado de Sendero Luminoso en la limeña calle Tarata (16 de julio de 1992), en el barrio de Miraflores, o el atentado en el club El Nogal de Bogotá (7 de febrero de 2003) - que dan cuenta del nivel de presencia de estos grupos en las capitales de Perú y Colombia, igualmente, en ambos casos la estrategia urbana termina fracasando en sus planteamientos. Es decir, la inicial y exitosa campaña periférica, de marcada impronta rural, se torna en derrota cuando se aspira a la centralidad, en buena medida, por factores compartidos en uno y otro caso. Así, la falta de legitimidad, la aparición de grupos paramilitares, las desventajas competitivas y la correlación de fuerzas en favor del Estado, gracias a una mayor beligerancia por parte de la Fuerza Pública — tal como sucede bajo las presidencias de Alberto Fujimori (1990-2000) o Álvaro Uribe (20022010) - desembocan, en su conjunto, trastocando la inicial aspiración insurgente.

Finalmente, en uno y otro caso, aunque con suerte dispar, hay un retorno a la condición periférica. Se produce un abandono de la guerra de movimientos y de retorno hacia la guerra de guerrillas, siempre, bajo una paulatina desideologización y una lógica de supervivencia que nada tiene que ver con los tiempos pasados de estos dos grupos armados, en donde, finalmente, el negocio cocalero acaba siendo la base fundamental que sostiene la lucha armada.

Dicho esto, la pregunta de investigación de partida para este trabajo sería: ¿cuáles fueron las dinámicas territoriales de la lucha armada protagonizadas por el PCPSL y las FARC-EP? La afirmación de inicio no es otra que la de presumir que uno y otro grupo experimentaron - aunque con diferencias sustanciales sobre algunas cuestiones que serán abordadas igualmente en estas páginas - procesos de lucha

razgo entre los sindicatos magisteriales. Tales intelectuales provincianos andina y mestiza, de hecho, pondrán en discusión la cuestión del indio, en su momento, planteada por Mariátegui. 
armada parecidos. Es decir, parten de un origen periférico y evolucionan de manera similar en la acumulación de fuerzas, con vistas a la centralidad, para, tras la respuesta del Estado, volver a ocupar los escenarios periféricos de partida, aunque bajo condiciones de mayor complejidad y debilidad.

El trabajo se organiza en torno a cuatro partes claramente identificadas. Inicialmente, se presentan los debates teóricos que se centran en estudiar las relaciones de la insurgencia con el territorio, de manera que conceptos como inaccesibilidad (inaccessibility) o recursos saqueables ${ }^{9}$ (lootable resources) y fuentes de financiación ilícita emergen con fuerza en la literatura sobre el estudio de insurgencias y conflictos armados en los últimos años.

Asimismo, se revisa parte de la literatura especializada sobre la relación entre territorio y violencia para los casos de los grupos armados de Colombia y Perú. Al respecto, se aprecia una ausencia en los trabajos académicos comparativos, de impronta cualitativa, en el estudio de las insurgencias, especialmente, en el campo de la Ciencia Política y de la Historia. Es decir, el objeto de estudio en sí es claramente prolífico y con muy notables aportaciones, se encuentra dominado por enfoques cuantitativos y generalistas, o en su defecto, por estudios de caso que rara vez abordan miradas compartidas con enfoques cualitativos y mayor nivel de detalle. En estas páginas se reivindica el valor agregado que, en las perspectivas comparadas sobre grupos insurgentes, y en especial, sobre formas y prácticas de la "lucha $\operatorname{armada}^{10}$ ", puede ofrecer la Geografía Política. Por ello, el análisis termina gravitando en torno a una compresión comparada de la particular relación territorial con la disputa que, frente al Estado, protagonizan las FARC-EP y el PCP-SL.

En tercer lugar, se procede con el análisis. Un análisis, mayormente descriptivo, que divide su estructura en tres momentos. Primero, se centra el origen de los dos grupos armados y en cómo la impronta periférica justifica su aparición y modula su inicial manera de emerger en el escenario de la violencia política de Colombia y Perú. Después, se atiende el proceso de evolución y, con ello, la capacidad de reclutamiento, la construcción de comunidades de legitimación y la consolidación de un conjunto de fuentes de financiación que fortalecen tanto a las FARC-EP como al PCP-SL. De hecho, sobre la base de lo anterior es que ambos grupos llegan a vislumbrar como posible una victoria frente el Estado que pasa por trascender hacia una guerra de posiciones y de movimientos que permita abrazar la centralidad y la derrota del enemigo estata ${ }^{11}$. Por último, el descrédito de los fundamentos de la lucha armada, la afectación que ésta tiene sobre la población civil, unido a reacciones gubernamentales de impronta beligerante, y a las que se suman fuerzas paralelas, como grupos paramilitares, convergen como una realidad que no solo imposibilita cualquier atisbo victorioso de la lucha insurgente, sino que obliga a los grupos armados a retornar nuevamente a espacios periféricos, desprovistos de cualquier aspiración de éxito.

9 La noción de recurso saqueable, en todo caso, ha de aceptarse como problemática con respecto a la financiación de otras insurgencias (petróleo, gas, minería ilegal). Sin embargo, su definición podría extrapolarse a la particularidad de los escenarios colombiano y peruano que, junto a Bolivia, concentran el espacio cocalero a nivel mundial.

10 Entiéndase por "lucha armada" la forma de disputa entre estos grupos insurgentes y el Estado.

11 Al respecto, aparece siempre la mirada funcionalista que sobre la guerra de guerrillas plantea el Che Guevara (1960). 
Las conclusiones buscan servir de corolario a los argumentos e hipótesis que se presentan en las siguientes páginas e, igualmente, invitan a considerar nuevas líneas de investigación en donde las miradas territoriales hacia la lucha armada, su evolución y lógica se entiendan como un importante caldo de cultivo desde el que seguir investigando, con rigor científico, un objeto de estudio tan prolífico y con tantas posibilidades, como es el de las insurgencias en América Latina.

\section{Marco teórico y estado del arte}

Los estudios sobre las guerrillas en América Latina ni mucho menos son nuevos. Existen miradas que se han centrado en explicar el fenómeno atendiendo a las razones de su surgimiento en términos de estructura socioeconómico o de acuerdo con las ventanas de oportunidad política que motivaron su aparición (Gott, 1971; Linz, 1986; Muller y Seligson, 1987; Muller, Seligson, Der Fu y Midlarsky, 1989; Wickham-Crowley, 1991; Bollen y Jackman, 1995; Ríos y Azcona, 2019; Krujit, Rey y Martín Álvarez, 2020). Asimismo, hay miradas de carácter subregional, con relación al caso centroamericano (Harto, 1991; Rouquie, 1994; Martí y Figueroa, 2006) o en el nivel andino, sobre todo, con respecto a los casos de Colombia (Sánchez [G.], 2009 [1987]; Pécaut, 2006; Pizarro, 2011) y Perú (Gorriti, 1999; Degregori, 2011, La Serna, 2012). Del mismo modo, existen apreciaciones en relación con el Cono Sur, en donde surgen movimientos que, pese a sus diferencias, discurren con relativas semejanzas, tal y como acontece con los Montoneros en Argentina, los Tupamaros en Uruguay o el Movimiento de Izquierda Revolucionaria en Chile (Ríos y Azcona, 2019). Como es de esperar, abundan los estudios de caso centrados en la comprensión holística que describe y explica la razón de ser del sinnúmero de grupos guerrilleros que han tenido lugar en América Latina desde 1959, a la vez que predominan miradas generalistas, de muy útil aportación, que se aproximan al fenómeno desde una perspectiva mayormente cuantitativa (Pinta, 2015).

De esta manera, en casi todos los ejercicios comparados, la razón analítica última viene a "reducir" su aportación a correlaciones y regresiones estadísticas que observan, desde el paradigma positivista, con enfoques estrictamente numéricos, centrados en la intensidad de la lucha armada, su evolución en el tiempo y la inscripción de ésta en contextos históricos mayormente generalizables. Sensu contrario, del mismo modo, en los innumerables trabajos pormenorizados de las insurgencias latinoamericanas solo unos pocos, de manera muy destacada, se han preocupado en comparar las experiencias colombianas y peruanas, tal y como es el caso de González y Maldonado (2017), observando la participación de las mujeres en el PCP-SL y las FARC-EP, o antes Maucerí (2001), preocupado por el papel de las elites y la política contrainsurgente.

Recientemente se han presentado trabajos bajo intentos de comparación que podrían inspirar el trabajo actual, si bien estos se realizan atendiendo otros casos que escapan del objeto de estudio andino. Así sucede con el trabajo de Rey y Martín Álvarez (2016), sobre la inserción en el sistema político de las experiencias guerrilleras de Uruguay y El Salvador; o con Azcona y Re (2015) y su trabajo sobre ETA, Brigadas Rojas, Tupamaros y Montoneros. 
Mirando a otros escenarios, cabe mencionar la aportación de Gutaj y Al (2017), comparando el PKK turco con el Ejército de Liberación Kosovar. Igualmente, destaca el proceso comparado de desarme en Mindanao y Myanmar que proponen South y Joll (2016), o sobre el movimiento de emancipación de Níger Delta y Boko Haram que presentan Aghedo y Osumah (2015). También cabría reconocer la mirada amplia que sobre el rol de las mujeres en las guerrillas desarrolla el trabajo de González-Pérez (2006).

Dicho esto, y tal y como se señalaba con anterioridad, se plantea que el recurso de la territorialidad y la mirada que ofrece la Geografía Política permite herramientas analíticas adecuadas para el ejercicio interpretativo y de comparación del fenómeno guerrillero latinoamericano. Para autores como Saleyhan, (2009), Linke, Witmer y O'Loughlin, (2012), O'Loughlin (2012), Basedau y Pierskalla (2013) o Linke y O'Loughlin (2015), el espacio, y concretamente, la concurrencia de particulares características de inaccesibilidad tras la que acontecen multitud de experiencias insurgentes, termina siendo la razón explicativa predominante a la hora de entender qué factores reposan tras el surgimiento de grupos armados y qué evolución, longevidad o desaparición.

En los últimos años, según Ríos (2017b), la Geografía Política se ha erigido como un campo prolífico para el estudio de la violencia en su relación causal con diferentes tipos de población (Raleigh y Hegre, 2009), de acuerdo a ciertas condiciones de pobreza (Hegre, Ostby y Raleigh, 2011), atendiendo a dimensiones fronterizas (Buhaug y Rød, 2006), con base en la proximidad de recursos como gas y petróleo (Basedau y Pierskalla, 2013) o en atención a la relación entre violencia y la pluralidad étnica de una comunidad (McDoom, 2014). De esta forma, en todos ellos, siempre el espacio aparece como telón de fondo explicativo con respecto al binomio violencia/territorio. Algo que, igualmente, proponen Horowitz (1985), Bracanti (2006), Schutte (2015) o Forø y Buhaug (2015), cuando afirman que escenarios geográficamente periféricos, de difícil accesibilidad y de mayor distancia con respecto de los centros económicos y políticos del país, operan como factor clave para comprender ciertas dinámicas de conflicto intraestatal.

Lo recién expuesto, innegablemente enlaza con la particular visión que presenta Mary Kaldor (1999), en relación con lo que denomina como "nuevas guerras", y que ha tenido mayor desarrollo, en el marco del análisis de los conflictos internos, a partir de los trabajos de autores como Collier y Hoeffler (2004), Kalyvas (2006), Snyder (2006) o Bates (2008), según los cuales los conflictos internos y, particularmente, las insurgencias deben estudiarse en su relación con el territorio, atendiendo a las lógicas derivadas de la economía política de la guerra que producen recursos saqueables (lootable resources) y fuentes de financiación ilícita.

En realidad, estas dos miradas, claramente complementarias, en el caso de las guerrillas latinoamericanas, y particularmente, en el caso de las FARC-EP y del PCP-SL, ayudan a entender su origen y su supervivencia en escenarios remotos. remotos. También, su incapacidad para consolidarse en escenarios urbanos, incluso cuando, con una mayor estructura y fortaleza militar, asumen la búsqueda de la centralidad operando en Lima, en Perú, y en el caso de Colombia, en las proximidades a grandes ciudades como Bogotá, Medellín o Cali.

Así, una secuencia periferia-centro-periferia se presenta, con sus matices y salvedades, en la evolución de FARC-EP y PCP-SL, cuya supervivencia en los últimos años responde tanto a la importancia de la condición periférica como de los 
recursos saqueables y las fuentes de financiación ilícita. En la misma medida, otras cuestiones como la reacción de la población civil, el tipo de respuesta gubernamental o la dimensión simbólica de la violencia han de ser tenidas en consideración para entender de mejor manera el conflicto armado de Colombia y Perú. Una mirada que, por su perspectiva comparada, ofrece un valor agregado a la ingente literatura existente que analiza espacio y violencia política, tanto en el caso colombiano (Echandía 2006; Salas, 2010, 2015; Ríos, 2016; Echandía y Cabrera 2018; Salas, Wolf y Camelo, 2018; Cairo et al., 2018) como en el de Perú (Kent, 1993; Kernaghan, 2009; Degregori, 2011; Taylor, 2017).

\section{Metodología}

Metodológicamente, este trabajo compara dos estudios de caso relacionados desde la similitud, la mirada cualitativa, y sobre la base de fuentes secundarias. Lo cierto es que la perspectiva comparativa no se trata, per se, de una metodología sino, más bien, de un marco metodológico que permite técnicas o enfoques diferentes. Particularmente, las siguientes páginas responden a un estudio de casos al estilo más estrictamente weberiano, si bien con una impronta mayormente descriptiva. Lo anterior, en la medida en que se comparan casos de forma global con el propósito último de llegar a conclusiones y generalizaciones modestas sobre orígenes, evolución y resultados de la relación espacio-lucha armada de dos grupos de marcada impronta periférica como son las FARC-EP y el PCP-SL.

La idea, por ende, es conducir al lector a generalizaciones sobre un proceso paralelo y similar entre estos dos actores que no busca sino alimentar un diálogo fructífero entre el investigador, el fenómeno y su evidencia (Caïs, 1997). Claro está, en el fondo existe una mirada manifiestamente interpretativa, de cierta naturaleza lógica, en donde es posible encontrar tendencias de asociación entre parte de lo sucedido en contextos de violencia política y conflicto armado de Colombia y Perú. Dos ejemplos que son similares en lo que respecta a la evolución territorial de la violencia y la lucha armada, a saber, inicialmente periférica, desarrollada en términos de centralidad y que, tras una derrota estratégica, nuevamente termina emplazada a una condición periférica.

Así, la influencia marxista, la violencia estructural y las tensiones políticas de inicio, alimentan el surgimiento de la insurgencia. Una insurgencia que, aunque se erige desde la idea de inaccesibilidad, paulatinamente va incorporando recursos ideológicos, militares, económicos y políticos que invitan al paso de una guerra de guerrillas hacia una guerra de movimientos. Ello con vistas a consolidar una posición territorial y establecer las bases de una posible conquista del poder político por las armas. En ambas experiencias, esto se hace con resistencias no solo de la Fuerza Pública, sino también producto de la población civil. Aunque la centralidad termina por ser acariciada en algún momento, no obstante, de manera más retórica que real, concurre una idéntica situación de infravaloración al poder del Estado, creciente deslegitimación y un contexto político de alta beligerancia que terminan por truncar el sueño de la revolución social. Un sueño truncado que se traduce en derrota militar en el caso del PCP-SL - desnaturalizado a modo de grupúsculo venido a menos en las últimas dos décadas-, y en una derrota estratégica para las 
FARC-EP que, entre otras cuestiones, permite entender el proceso de diálogo y posterior Acuerdo de Paz suscrito con el Gobierno Colombiano en $2016^{12}$.

\section{Origen: fundamentos ideológicos e impronta periférica}

El origen de las FARC-EP y del PCP-SL presenta importantes similitudes al igual que particulares diferencias. Como se verá a continuación, dicho origen se inscribe, para ambos casos, en la década de los años sesenta en dos escenarios olvidados de la historia política colombiana y peruana como son, respectivamente, Marquetalia y Ayacucho. En los dos el contexto es de confrontación social y política y, ambos grupos tienen una marcada influencia del marxismo, más de base agraria y campesina en el caso de las FARC-EP, y de impronta maoísta en el caso del PCP-SL. En estas dos experiencias aparece inicialmente la necesidad de empoderar una categoría subalterna, denostada en el nivel central del Estado: el campesino y el indio en Perú - aunque no en exclusiva, habida cuenta de la importancia del colectivo de maestros y profesores, por ejemplo-, y el mismo campesino en Colombia. Igualmente, coinciden liderazgos personalistas que son clave, tal y como es el caso de "Manuel Marulanda" en la guerrilla colombiana y de Abimael Guzmán en la peruana, si bien el sentido colectivo siempre será mucho más fuerte en el caso del grupo colombiano ${ }^{13}$. El trabajo con bases de apoyo y la paulatina conformación del grupo se desarrolla en las dos experiencias, hasta 1980, aproximadamente. Las FARC-EP, operan más bien como una guerrilla a modo de grupo de autodefensa campesina (Pécaut, 2006), evitando el conflicto y la acción armada (Aguilera, 2014). Mientras, en el PCP-SL, el proceso se desarrolla a través de la conformación y depuración de un grueso político, teórico e intelectual, no armado, entre 1969 y 1980, y que alimenta lo que después será denominado la matriz del marxismoleninismo-maoísmo-pensamiento Gonzalo (Ríos, 2018).

En cualquier caso, en cuanto a las diferencias, cabe destacar que mientras que las FARC-EP, en sus inicios, terminan siendo conformadas mayoritariamente por campesinos, en el PCP-SL hay una marcada impronta pedagógica, de maestros de escuela y profesores universitarios que sirven de "vanguardia" a unas bases igualmente campesinas y quechua-hablantes.

Las FARC-EP aparecen en escena por primera vez en 1966, autodenominadas así y tomando como hito fundacional lo acontecido el 27 de mayo de 1964, cuando se produce una "Operación Marquetalia", por medio de la cual, el Gobierno colombiano buscaba sofocar una revuelta de campesinos levantados en armas que, en un espacio denominado por éste como "repúblicas independientes", entendían que el Estado no les representaba. La reivindicación de Marquetalia resultaba extensible a otros escenarios como los de Tierralta, El Pato o Guayabero, todos próximos

12 En términos de lógica de la lucha armada, cuando se refiere a derrota estratégica se hace referencia a la imposibilidad de conseguir los objetivos del grupo armado inicialmente identificados y que motivaron la confrontación contra el Estado. Cuando se hace referencia a la derrota militar quiere decirse que el grupo armado ha quedado desarticulado y, a lo sumo, reducido a niveles mínimos de estructura y capacidad.

13 En el caso del PCP-SL durante toda la década de los setenta, antes del inicio de la lucha armada, se va construyendo un culto personalista en torno a la figura de Abimael Guzmán (Roncagliolo, 2007). Todo lo contrario, en las FARC-EP siempre predominó un liderazgo más colegiado. De hecho, a partir de la VI Conferencia Guerrillera se crea el Secretariado y el Estado Mayor Central como órganos directivos de la guerrilla. 
entre sí, donde el marxismo había calado hasta el punto de que allí persistían los grupos de autodefensa campesina que se habían levantado contra el Gobierno a inicios de los años cincuenta - en el marco de una guerra civil partidista que dejó consigo 200.000 muertos (Bushnell, 2012) — y que había desatendido la línea general de desmovilización que otros grupos, de cariz liberal, habían asumido también a mediados de los cincuenta.

De este modo es que se entiende la marcada impronta agraria y campesina que ideológicamente siempre ha acompañado a las FARC-EP. Una impronta cuya teorización ha sido endeble — pues las FARC-EP nunca tuvieron grandes intelectuales en su seno-, pero que no es óbice para entender que ha sido en los enclaves rurales, campesinos y olvidados del sur y del suroccidente de Colombia, donde ha estado presente, generalmente, su referente simbólico-territorial más significativo.

Hay que recordar que el Estado colombiano en los años cincuenta y sesenta tenía como prioridad la conformación de sus bases estructurales e institucionales, de manera tal que sus esfuerzos estaban orientados a la construcción de carreteras e infraestructura y a erigir, aunque fuese incipientemente, un Estado social de mínimos. De este modo, la lucha contra grupos insurgentes presentes en enclaves remotos, de ningún interés para el establishment colombiano, estaba lejos de ser un problema en la agenda de gobierno (Bushnell, 2012; Pécaut, 2006).

Con apenas 350 combatientes en 1964 y menos del millar a finales de los 1970, estos años son de "crecimiento vegetativo" (Aguilera, 2010), de forma que el promedio de tomas de municipios y acciones armadas apenas se reduce a un caso por año. Dicho de otra manera, las FARC-EP no eran ni en los 1960 ni en los 1970 una guerrilla que buscase la oposición frontal con el Estado en términos estrictos de lucha armada. Todo lo contrario, son años de organización y construcción de bases organizacionales y territoriales de funcionamiento, en torno a un líder, "Manuel Marulanda Vélez", que toma decisiones en el marco de un órgano colegiado como, desde 1978, es el Secretariado, aunque supeditado al Partido Comunista al menos hasta el año 1982. Desde entonces, la lucha armada prevalece frente a una formación política organizada en torno al Partido Comunista Colombiano, primero, y el Movimiento Bolivariano, después.

Ayacucho, como Marquetalia, en los años 1960 se trataba de un contexto tan olvidado como politizado, fruto del encono social y la confrontación con el Estado en un marco político restrictivo de derechos. El comunismo a Ayacucho, en buena medida, había llegado a través del comité regional del Partido Comunista Peruano, fundado en 1928, y cuyo nombre era el mismo que el de su fundador: José Carlos Mariátegui. Desde el año 1963, un filósofo y profesor universitario llamado Abimael Guzmán Reinoso - el futuro "Camarada Gonzalo" - era uno de sus máximos exponentes. Un intelectual de marcada impronta maoísta que a partir de la ruptura sino-soviética de 1962, se integraría dos años después en el ala filo-china del PCP, denominada inicialmente como "Bandera Roja" y en oposición a la facción filomoscovita de "Unidad", "colaboracionista", entre otras cuestiones, con el golpe de Estado de 1968.

Bajo este contexto, Ayacucho, tal y como han señalado buena parte de los trabajos de Degregori $(2011 ; 2015)$, imbricaba un olvido y un ostracismo con base en una marcada ausencia de infraestructuras, a la par de una notable crisis latifundista, agravada por la concurrencia de terceros polos regionales de desarrollo. De hecho, dos de las provincias ayacuchanas como Cangallo y Víctor Fajardo estaban entre 
las más pobres del país durante los años sesenta y setenta, y el departamento de Ayacucho, en general, se caracterizaba por ser una suma de explotación terrateniente, opresión servil y discriminación étnica. Elementos que para Sánchez [M.] (2015) darían suficiente cuenta de por qué la población campesina se convirtió en el terreno fértil para el surgimiento de discursos como los que abrazaría el PCP-SL. Algo apreciable si se atiende la razón por la cual Ayacucho, de acuerdo con todo lo anterior, se encontraba entre los tres registros de escolarización y analfabetismo más bajos de todo el país. Niveles que se mantendrían casi al 50\% a inicios de la década de los 1980, duplicando el promedio nacional (Degregori, 2011).

En definitiva, un alto nivel de politización del malestar, unido a una ingente violencia estructural encontraban un perfecto aglutinador en la universidad pública de la región: la Universidad Nacional de San Cristóbal de Huamanga (UNSCH). Esta universidad reabrió sus puertas en los cincuenta y fue un catalizador de ideas y reclamos progresistas. Rápidamente, pasó de 228 estudiantes matriculados en 1959 a 7.209 en 1978 y fue estrechando vínculos con sectores populares como la Federación de Barrios de Ayacucho (Ríos y Sánchez, 2018). Este binomio estaría detrás de las luchas por la gratuidad de la enseñanza de 1969, y en ambos casos cabía apreciar una marcada influencia de la Facción Roja dirigida por Abimael Guzmán. Ésta era perteneciente a Bandera Roja, y desde 1965 conceptualizaba el carácter semifeudal y semicolonial de Perú, lo que a su juicio creaba las condiciones objetivas que alimentaban la revolución y la necesidad de promover ésta a través de una guerra popular con tres elementos: partido, ejército y frente amplio. Tres valores que serían punta de lanza en el disenso que experimenta Bandera Roja desde mediados de 1969, y que deja consigo la aparición, ya sí, stricto sensu, del Partido Comunista del Perú-Sendero Luminoso, desde 1970 (Valenzuela, 2019). Una formación política que durante toda la década de los 1970 se dedicaría a consolidar su estructura y organización, de forma que su primera acción armada no llegaría hasta mayo de 1980, coincidiendo con el retorno de la democracia a Perú.

Es decir, es posible encontrar en el caso peruano un mismo componente periférico, de alta politización y confrontación social, de marcada presencia del marxismo y también de escasa o, mejor dicho, nula confrontación armada. No obstante, y si bien existen muchas similitudes con lo expuesto anteriormente para las FARCEP, hay una diferencia sustancial con la mirada táctica que desarrollaba la guerra popular. Antes que nada, había que ahondar, según el PCP-SL, en las contradicciones que justificaban la revolución, teorizando y problematizando sobre ellas y, finalmente, politizando a las bases sociales de apoyo sobre la inevitabilidad de la lucha armada. Una cuestión ésta que haría que Sendero Luminoso invirtiese todos sus esfuerzos en aglutinar y formar militantes que ya, para 1980, estarían convencidos del salto a la guerra popular y la derrota última del Estado a través de las puntas de lanza que ofrecía el campesinado quechua-hablante y los estudiantes de escuelas y universidades públicas.

\section{Desarrollo de la lucha armada: la búsqueda de la centralidad}

El inicio de la lucha armada en sentido estricto, en ambos casos, se puede ubicar en la década de 1980 y concretamente hacia 1982, si bien es producto y parte de dos orientaciones diferentes. En los dos casos se aprecia un proceso de acumulación de 
fuerzas que implica mayor nivel de reclutamiento, mayor despliegue territorial y ya sí, una mayor capacidad de confrontación en el ejercicio de lucha armada. Asimismo, escapando de sus áreas de influencia, tanto las FARC-EP como el PCP-SL van, poco a poco, dejando atrás la guerra de guerrillas inicial y acaban disponiendo de capacidad suficiente para ir desplazando de ciertos enclaves a la institucionalidad local para instaurar una suerte de hegemonía local paraestatal. Finalmente, en ambos casos, llegan a buscar la centralidad en su sentido más literal, esto es, volcando los esfuerzos en una tarea envolvente, que tiene como último propósito ganar protagonismo y visibilidad en la capital. De hecho, los mencionados atentados en la calle Tarata de Lima y en el club El Nogal de Bogotá son dos acontecimientos que visibilizan una presencia capitalina que, en todo caso, habrá que relativizar.

En el caso de las FARC-EP, un momento clave es el período que transcurre entre 1982 y 1993, pues entre esos años tienen lugar la VII y la VIII Conferencia Guerrillera de esta guerrilla, marcando un cambio en el devenir de la lucha armada y muy especialmente, en la impronta territorial de la misma. En el transcurso de esta década es cuando se diseña el proceso de acumulación de fuerzas, la intensificación del reclutamiento, el desdoblamiento de frentes y la necesidad de trascender de la guerra de guerrillas y orientar la lucha armada hacia una guerra de movimientos. Al respecto, el incremento de los instrumentos de extorsión y de secuestro, pero también el auge del narcotráfico en Colombia, van a tener mucho que ver en cuanto a este proceso expansivo.

Para entender lo anterior no se pueden obviar diferentes elementos de análisis. En primer lugar, hay que tener en cuenta el proceso de convergencia fallido que suponen la Coordinadora Nacional Guerrillera (1985) y la Coordinadora Guerrillera Simón Bolívar (1987) tras el intento de Acuerdo de Paz en 1984 por parte de la presidencia de Belisario Betancur con las FARC-EP y el M-19. Lo anterior, en tanto que la profunda heterogeneidad de interpretaciones de la violencia y su superación imposibilita cualquier atisbo de convergencia, incluso, tras el proceso desmovilizador de 1990, que mantendrá al ELN y las FARC-EP como únicos grupos insurgentes en activo.

De otro lado, hay que tener en consideración que entre mediados de los 1980 y mediados de los 1990, las FARC-EP llegan a disponer de más de treinta frentes de guerra, incluso, como señala Aguilera (2014), llegando al medio centenar de estructuras, con casi 6.000 efectivos en sus filas. Ello hace que la lucha armada que abanderan las FARC-EP se disemine por buena parte de la geografía del país, con especial predilección por la cordillera oriental de los Andes y los alrededores de las ciudades de Bogotá, Medellín y Cali. Igual va a suceder con las zonas fronterizas con Venezuela y Ecuador, y los corredores estratégicos de gran valor para el tráfico de armas y droga. Chocó, con acceso al Pacífico, queda libre de paramilitares - a diferencia de la región de Urabá-, y copado por estructuras herederas del inicial Frente 5 de las FARC-EP. Caquetá y Huila se consolidan como bastiones nucleares, unidos a Cauca y Nariño, para controlar todo el resto de litoral Pacífico y la frontera con Ecuador, respectivamente. Asimismo, el corredor colombovenezolano pasa a ser controlado por unas FARC-EP que fortalecen su presencia en los departamentos de La Guajira, Cesar, Norte de Santander, Arauca, Vichada y Guainía (Pécaut, 2008).

Lo expuesto, además, se entiende por otras razones. En primer lugar, por la superación del debate interno sobre cuál debía ser la posición de las FARC-EP en 
relación con el cultivo cocalero e incluso con el procesamiento y distribución de la droga, sobre todo, una vez desmantelados los cárteles, primero de Medellín (1993) y después de Cali (1996). Y es que la muerte del "ideólogo" de las FARC, "Jacobo Arenas", escéptico con respecto a cualquier proximidad al negocio cocalero, coincide con el auge de la figura beligerante del "Mono Jojoy" y el fortalecimiento de los conocidos como "frentes ricos", ubicados en los escenarios cocaleros en donde reposaban los bloques Oriental y Sur de las FARC-EP.

Dos estructuras cada vez más próximas a un negocio de la droga que les nutría de recursos económicos y que permitieron una mayor capacidad operativa, traducida en las primeras derrotas militares de la Fuerza Pública a manos de las FARCEP. Algo que sucedería en la segunda mitad de los 1990, en escenarios como Puerres, Las Delicias o Vistahermosa (Echandía, 1999). Lo anterior conduce a que tras cuatro años de descrédito gubernamental de la presidencia de Ernesto Samper (1994-1998), fruto de la filtración de cinco millones de dólares en su campaña electoral provenientes del cártel de Cali, las FARC-EP alcancen unas cifras que en Colombia no tenían precedente hasta ese momento: 356 acciones armadas en 186 municipios con más de 10.000 efectivos (ODHDIH, s.f.).

Figura 1. Frentes de las FARC-EP creados entre 1960 y 1996

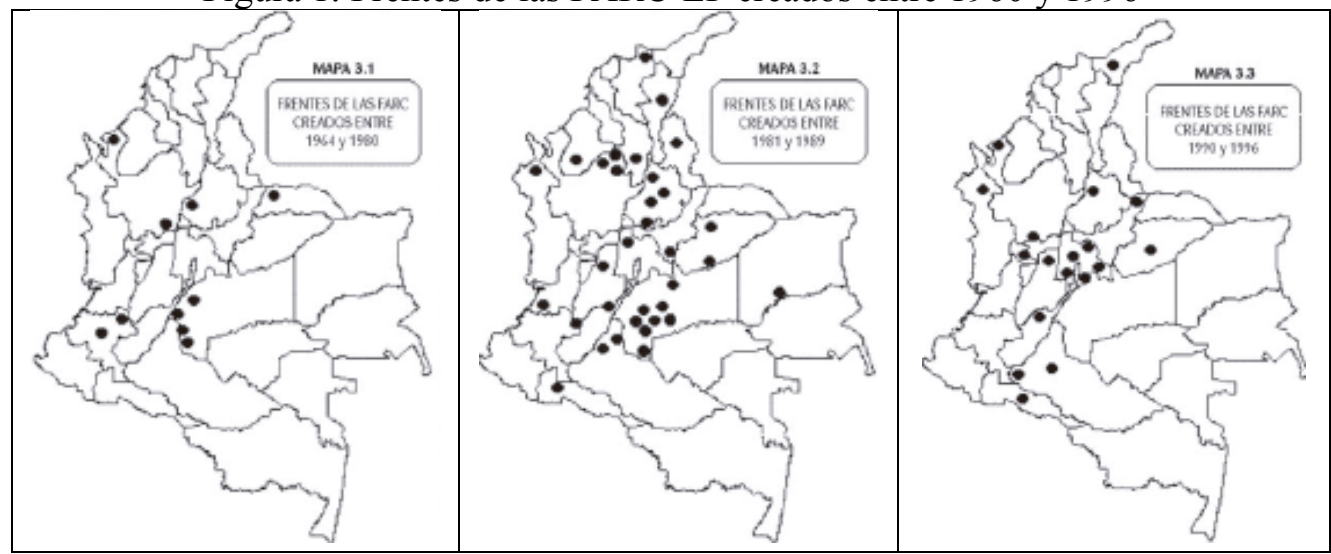

Fuente: Pécaut (2008, p.31).

$\mathrm{Si}$ a lo mencionado se suman miles de alzados en armas pertenecientes a grupos paramilitares e integrantes del ELN, es que se entienden las continuas menciones a Colombia como arquetipo de la noción de Estado fallido (failure state) en América Latina hacia finales de los noventa (Rotberg, 2004). De hecho, así es que se entiende la necesidad que vislumbró Andrés Pastrana, como nuevo presidente de Colombia en 1998, de abrir un espacio de diálogo que, cuando menos, pusiese fin al conflicto que el Estado colombiano mantenía con las FARC-EP. Sin embargo, dicho proceso, conocido como el Caguán, no fue sino un intento frustrado más de negociación que transcurrió, a lo largo de 1.139 días, entre enero de 1999 y febrero de 2002, sin éxito alguno.

Durante ese tiempo, el gobierno pasó del 3.8 al 4.4\% del gasto público en seguridad y defensa, impulsó un plan de modernización de la Fuerza Pública y suscribió el Plan Colombia con Estados Unidos (Ríos, 2017a). Asimismo, el número de ope- 
rativos del Ejército contra esta guerrilla se incrementó notablemente mientras formalmente existía el diálogo de paz, pasando de 201 acciones en 1998 a 244 en 1999, 352 en el año 2000 y 660 en 2001 (ODHDIH, s.f.).

A la vez, las FARC-EP seguían desdoblando frentes, superando los 80 frentes de guerra y los 18.000 efectivos, lo que supondría el cénit de su capacidad de combate, de manera tal que si en 1999 se contabilizaban 343 acciones armadas en 194 municipios, en 2002 llegaban a las 1.042 acciones en 346 municipios (ODHDIH, s.f.). Esto, gracias en buena parte a los más de 1.000 millones de ingresos anuales procedentes de droga, extorsión y secuestro (Aguilera, 2014; Bejarano y Pizarro, 2003). Así, con una agenda impracticable de 12 temas de negociación y 48 subtemas se ponía fin al proceso de diálogo en febrero de 2002.

El resultado iba a ser un escalamiento del conflicto armado sin precedentes, en el que las FARC-EP iban a poner en marcha un plan de asfixia sobre las grandes ciudades del país, y muy especialmente a Bogotá, desde la primavera de 2002. De esta manera, el punto máximo de visibilidad de esta apuesta por la centralidad sería el atentado que sufriría el exclusivo Club El Nogal de Bogotá, ubicado en la carrera séptima con la calle setenta y ocho, en donde morirían, el 7 de febrero de 2003, un total de 36 personas, y a las que se sumarían otras 200 heridas. A la vez, las FARCEP buscarán, igualmente, consolidar su presencia territorial en ciudades nucleares del país como Medellín o Cali y encontrarán, sobre todo en el paramilitarismo, su principal enemigo armado (Duncan, 2006; Ríos, 2017b).

En el caso del PCP-SL, el proceso de conquista de la centralidad resulta mucho más rápido e intenso que en el caso de las FARC-EP, tal vez, primero, por lo focalizado del punto de aparición inicial, circunscrito casi en exclusiva a Ayacucho y, por ende, no disperso territorialmente, $y$, segundo, por el eficaz trabajo de acumulación de bases que, entre finales de los 1960 y toda la década de los 1970, había llevado a cabo el partido ${ }^{14}$. Solo, tras lo anterior, se llegaba al 17 de mayo de 1980, cuando en el poblado de Chuschi, en la sierra ayacuchana, el día en el que Perú retornaba a la democracia tras doce años de dictadura militar, unos jóvenes irrumpieron en la gobernación distrital para maniatar al encargado de la vigilancia y quemar y destruir todo el material electoral (ánforas y padrón) en plena plaza pública, mientras lanzaban arengas con el inicio de la lucha armada.

Una importante diferencia, nada baladí, entre el inicio de la ofensiva contra el Estado entre las FARC-EP y el PCP-SL reposa en que en el primero de los casos, la confrontación era producto de un escenario de violencia política que se remontaba, incluso, a la segunda mitad de los años 1940. Por su parte, en lo que respectaba a Sendero Luminoso, lo cierto es que había un total desconocimiento de parte del Estado de qué era y qué buscaba ese grupúsculo, inicialmente infravalorado, y que en no mucho tiempo iba a ser la mayor amenaza experimentada contra la institucionalidad democrática peruana (Ríos, 2019).

En buena medida, lo anterior se entiende en tanto y en cuanto mientras las FARC-EP asumían un modelo de guerrilla guevarista, el PCP-SL "se fundía en la masa", al más puro estilo de la guerra popular prolongada encabezada por Mao Tse-Tung, siempre con el propósito de hacer valer la máxima de tener "ojos y oí-

14 En el caso del PCP-SL, a diferencia de las FARC-EP, lo que prima es el partido, de manera que la acción armada siempre está supeditada a la acción y estructura política, cosa diametralmente a lo que sucede en las FARC-EP a partir de 1982. 
dos en todas partes". De una manera mucho más clara y notoria, para Sendero Luminoso la toma del poder, si de emular la experiencia china se trataba, pasaba necesariamente por ir del campo a la ciudad, de manera que el mejor modo pasaba por consolidar su presencia en la periferia limeña — si bien, siempre sin perder nunca de vista el sentido de la realidad peruana-.

Entre 1980 y 1982, el PCP-SL se expande por toda la provincia de Ayacucho, y fundamentalmente sobre Cangallo o Víctor Fajardo sin que el dispositivo de policía dirigido a la zona pudiera hacer nada. El desinterés político unido al desconocimiento del enemigo y la ineficacia de la respuesta dieron un importante balón de oxígeno a Sendero, que rápidamente se extendería por el corredor sur-andino peruano, igualmente, gracias al amplio dispositivo de obtención de recursos, principalmente, provenientes del robo y la extorsión.

Figura 2. Evolución territorial de Sendero Luminoso, 1981-1990

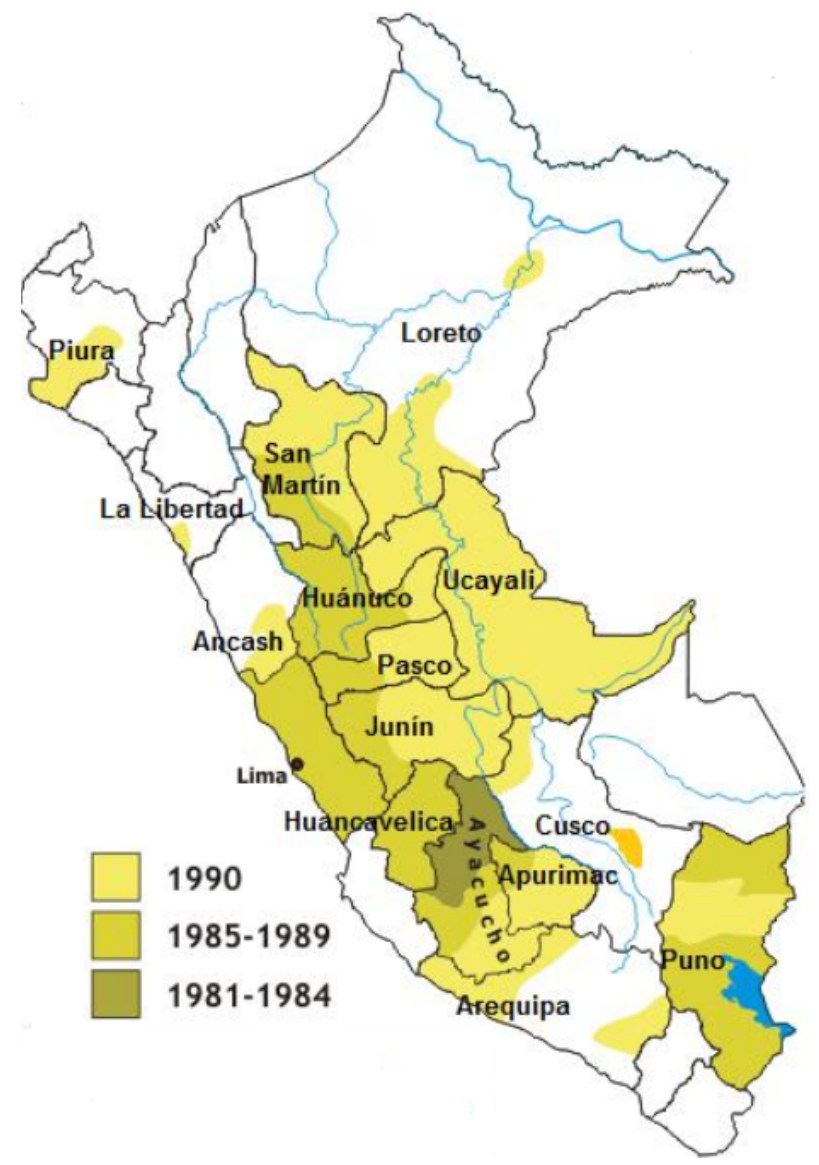

Fuente: Commons (s.f.).

Durante estos dos años y medio el PCP-SL acumuló poder, expulsó a la institucionalidad local e impartió justicia draconiana a través de una violencia que buscaba poner fin a los males endémicos de la sociedad peruana: abuso de las autorida- 
des, corrupción local, violencia familiar, adulterio o alcoholismo, entre muchos otros. Sendero no dialogaba, Sendero imponía un modo de vida y una conciencia revolucionaria a sangre y fuego que, si bien inicialmente le permitió disponer de manera rápida de miles de correligionarios, más pronto que tarde iba a experimentar el descrédito y la desafección de miles de campesinos que no encontraban en la retórica senderista la verdadera realidad que abrazaba su cotidianeidad (Degregori, 2011; Ríos y Sánchez, 2018).

A pesar de lo expuesto, la búsqueda de la centralidad del poder político a la que aspiraba Sendero Luminoso se mantuvo entre 1983 y 1985, si bien son años en los que cambia la respuesta del Estado, de manera que son las Fuerzas Armadas y no la Policía la que se encargará de combatir contra el enemigo senderista. De esta forma, el estado de excepción se generaliza y el Gobierno vuelca sus esfuerzos en disputar a Sendero el nuevo poder por el cual el grupo armado había suplantado por completo la institucionalidad del Estado en el nivel local. Es decir, lo que sucede con las FARC-EP y el Gobierno colombiano casi dos décadas después de la declaración de intenciones de 1982, en Perú se había acelerado de manera vertiginosa y era una realidad en apenas tres años.

De hecho, entre 1983 y 1985 se producen masacres y matanzas perpetradas por uno y otro bando en la contienda, concentrándose un pico de violencia que se traduce en más de 6.000 desapariciones del lado de Sendero Luminoso y otras tantas de parte de la Fuerza Pública (Ríos y Sánchez, 2018). Sea como fuere, se trata todavía de una violencia mayormente centrada en el enclave en disputa de Ayacucho, sobre la base de poblaciones campesinas, pobres y quechua-hablantes. Tal y como reconoce la CVR (2003), solo en 1984 se produjo el 19\% del total de muertes y desapariciones que acontecieron en todo el conflicto armado peruano ${ }^{15}$. Aquí será cuando se escriben algunas de las páginas más oscuras de la violencia en Perú, tal y como fueron las masacres a cuenta del Estado en Socos (noviembre de 1983), Pucayacu (agosto de 1984), Putis (diciembre de 1984) y Accomarca (agosto de 1985) (Ríos y García de las Heras, 2019); o bajo responsabilidad de Sendero Luminoso, como sucedió en Lucanamarca o Huancasancos, en abril de 1983.

Desde 1985, el conflicto entra nuevamente en una etapa de diseminación de la violencia en donde Sendero vuelve a la carga con secuestros, torturas y asesinatos selectivos que, especialmente, se intensificarían en la segunda mitad de la década de los ochenta. De igual manera, el conflicto armado se escalaba de parte de la Fuerza Pública, aumentando notablemente el número de muertes producidas por ellos, y también las ejecuciones arbitrarias y los casos de tortura (Ríos y García de las Heras, 2019). Bajo el gobierno del aprismo, con Alan García a la cabeza, la violencia política se extendía por la geografía peruana, más allá de Ayacucho, afectando decididamente a las provincias de Puno, Junín y el Valle del Alto Huallaga este último enclave, de marcada impronta cocalera ${ }^{16}$.

Este proceso de desdoblamiento de frentes de lucha armada se inscribe en la estrategia senderista de desarrollo de la guerra de guerrillas y conquista de bases de apoyo, aunque empezaba a concitar disputas frontales en enclaves rurales con ase-

15 Un conflicto que, según las cifras oficiales, deja más de 69.000 muertes y 30.000 desapariciones forzadas (CVR, 2003).

16 Conviene enfatizar que, a diferencia con las FARC-EP, el PCP-SL siempre interpretó que su participación en el negocio cocalero era circunstancial y justificada por la lucha contra el Estado. 
sinatos selectivos y acciones propagandísticas en las grandes ciudades. Así, hacia 1989, después de la celebración del primer congreso del PCP-SL, y sobre la base de un pie de fuerza de más de 10.000 efectivos y una presencia en la periferia limeña cada vez más notoria — véase San Juan de Lurigancho—, Abimael Guzmán consideraba que la guerra en Perú había llegado a un equilibrio estratégico, de manera que solo quedaba dar un salto hacia delante.

Es decir, a partir de 1988, y especialmente, 1989, Sendero Luminoso lleva la violencia a Lima - en donde se contabilizan hasta tres acciones diarias - al entender que la lucha armada debe desencadenarse en la capital (Wills, 2003). Una capital que encontraría en el atentado de la calle Tarata, localizada en el reconocido barrio de Miraflores, un giro drástico en la posición de Lima con respecto a un conflicto al cual, durante años, la elite limeña le había dado la espalda. Ese día, el 16 de julio de 1992, un coche bomba estallaría pasados unos minutos de las 9 pm, dejando consigo 25 muertos y más de 200 heridos.

Gráfico 1. Número de muertes y responsables en el conflicto armado peruano, 1980-2000

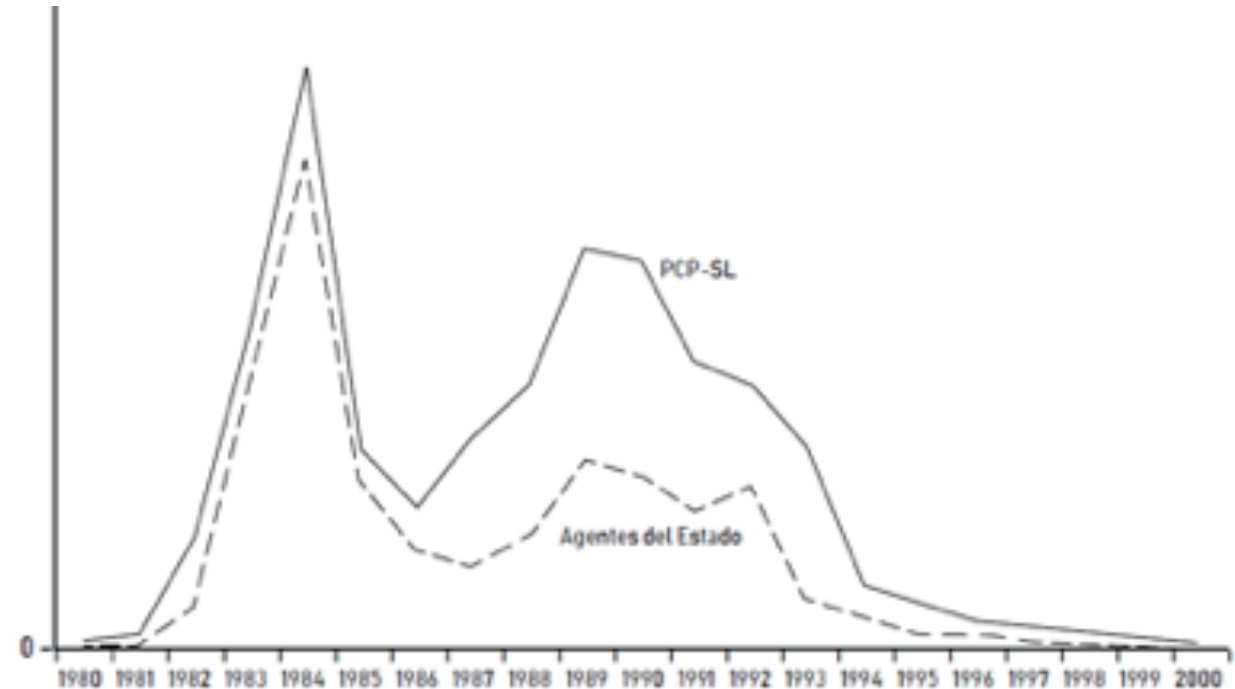

Fuente: Ríos y Sánchez (2018,p.91).

\section{Decadencia y retorno a la periferia}

En ambos casos el retorno a la periferia se produce como resultado de una derrota estratégica, en tanto que se frustran las aspiraciones iniciales, si bien, además, en el caso del PCP-SL concurre una derrota militar. El retorno a la periferia vuelve a traer a colación, de un lado, la importancia de la inaccesibilidad, esto es, de escenarios de difícil acceso y notable distancia con los centros decisorios políticos del país, y por otro lado, la maldición de los recursos, a partir de lo cual los grupos insurgentes de Colombia y Perú experimentan un proceso de desideologización, en 
donde la extorsión, pero sobre todo la proximidad al negocio cocalero se torna como el rédito económico que sostiene la supervivencia de la "lucha armada".

La centralidad, en realidad, debe relativizarse, pues cuando acontece, tanto en Perú como en Colombia, coincide en el tiempo con el inicio de un auge y modernización en la capacidad de respuesta policial y militar, fruto de un proceso paulatino de avance en la eficacia de la lucha contrainsurgente y el recurso de la inteligencia (Ríos y Zapata, 2019). El debilitamiento de las estructuras de las FARC-EP y del PCP-SL se agrava en el momento en el que las cúpulas de su comandancia empiezan a sentir, como nunca, el resultado de este proceso de avance en la respuesta del Estado. Así, basta con observar el impacto que en las FARC-EP genera la baja de importantes comandantes como "Raúl Reyes", "Mono Jojoy" o "Alfonso Cano", muy similar al que supuso la captura del líder senderista, Abimael Guzmán, en septiembre de 1992.

De otra parte, no se puede pasar por alto ni la escasa legitimidad de las bases de apoyo de estos grupos armados, especialmente en contextos rurales, ni el debilitamiento que generan, en la estructura armada, las respuestas a modo de autodefensa, organizadas en torno a las Autodefensas Unidas de Colombia y otros grupos paramilitares (Ronderos, 2014; Ríos, 2017b) y los Comités de Autodefensa en el caso de Perú (CVR, 2003; Degregori, 2011). Igualmente, el repliegue y debilitamiento de Sendero Luminoso y las FARC-EP vendrán igualmente impulsados por dos políticas de "mano dura", centradas fundamentalmente en la superación de la violencia a través de la derrota del enemigo insurgente, tal y como son las de Alberto Fujimori (1990-2000) y Álvaro Uribe (2002-2010).

La llegada de Álvaro Uribe a la presidencia colombiana en agosto de 2002 impulsa la que se conocerá como Política de Seguridad Democrática (PSD), la cual, durante ocho años, se alimentará de más de 8.000 millones de dólares de inversión directa en seguridad y defensa, y a los que se suman otros 8.000 millones, hasta 2012, de cooperación militar proveniente exclusivamente de Estados Unidos (Otero, 2010; Ríos y Zapata, 2019). Lo anterior, fruto de un incremento de casi el 40\% del pie de fuerza pública, que entre Policía y Ejército pasa de los 313.000 efectivos a 478.000 integrantes, y de la inversión de más de un 4\% del PIB anual a cuestiones estrictamente de seguridad y defensa (MINDEFENSA, 2011). También, se fortalece la capacidad de combate aérea y nocturna, y Colombia se convierte en la segunda fuerza militar per cápita más numerosa del continente. Además, se ponen en marcha iniciativas de mayor intercambio y cooperación entre los diferentes cuerpos militares y se desarrolla muy notablemente la inteligencia y la estrategia contrainsurgente en el seno del Ejército colombiano (Medellín y Rangel, 2010; Ríos, 2017a).

El resultado no se hace esperar y a los dos años de PSD, en torno a finales de 2004, las FARC-EP prácticamente han desaparecido de todo el centro del país, esto es, de los departamentos de Cundinamarca, norte de Meta, Boyacá, Caldas, Risaralda y Quindío, y de casi toda la costa Atlántico, con la excepción del sur de Bolívar y parte de La Guajira. El proceso de hostigamiento contra la guerrilla colombiana tras ocho años de PSD termina siendo notorio, hasta el punto de que su presencia territorial y de efectivos se reduce a la mitad, lo que equivale a 8.500 combatientes y una presencia en poco más de 120 municipios de los 1.120 que conforman el país (Ríos, 2017b). Todo lo anterior, sin dejar de lado el factor coad- 
yuvante que jugaría la dudosa alianza entre Fuerza Pública colombiana y estructuras paramilitares, al menos, hasta el año 2006.

Este curso de paulatino debilitamiento, ya sin retorno, ha sido abordado por trabajos como los de Echandía (2013) o Salas (2015). A tal efecto, por ejemplo, Ríos (2016a; 2016b) apunta específicamente a un doble proceso de periferialización y narcotización. Periferialización, en la medida en que las FARC-EP pierden la centralidad en detrimento de un retorno a sus tradicionales bastiones fronterizos, sobre todo, del nororiente y del suroccidente. Es más, de las 724 acciones guerrilleras que se apuntaba que habían sido contabilizadas en 2010, dos terceras partes tuvieron lugar exclusivamente en departamentos de frontera. Del mismo modo, acontece un refugio de la guerrilla hacia escenarios de marcada impronta cocalera, lo cual conectaría con la desideologización insurgente que, igualmente, en algún momento fue apuntada previamente. Dicho esto, si en 2002 apenas el $20 \%$ de la presencia territorial de las FARC-EP era cocalera, esa proporción se incrementa en un $250 \%$ ocho años después.

Figura 3. Proceso de periferialización de las FARC-EP
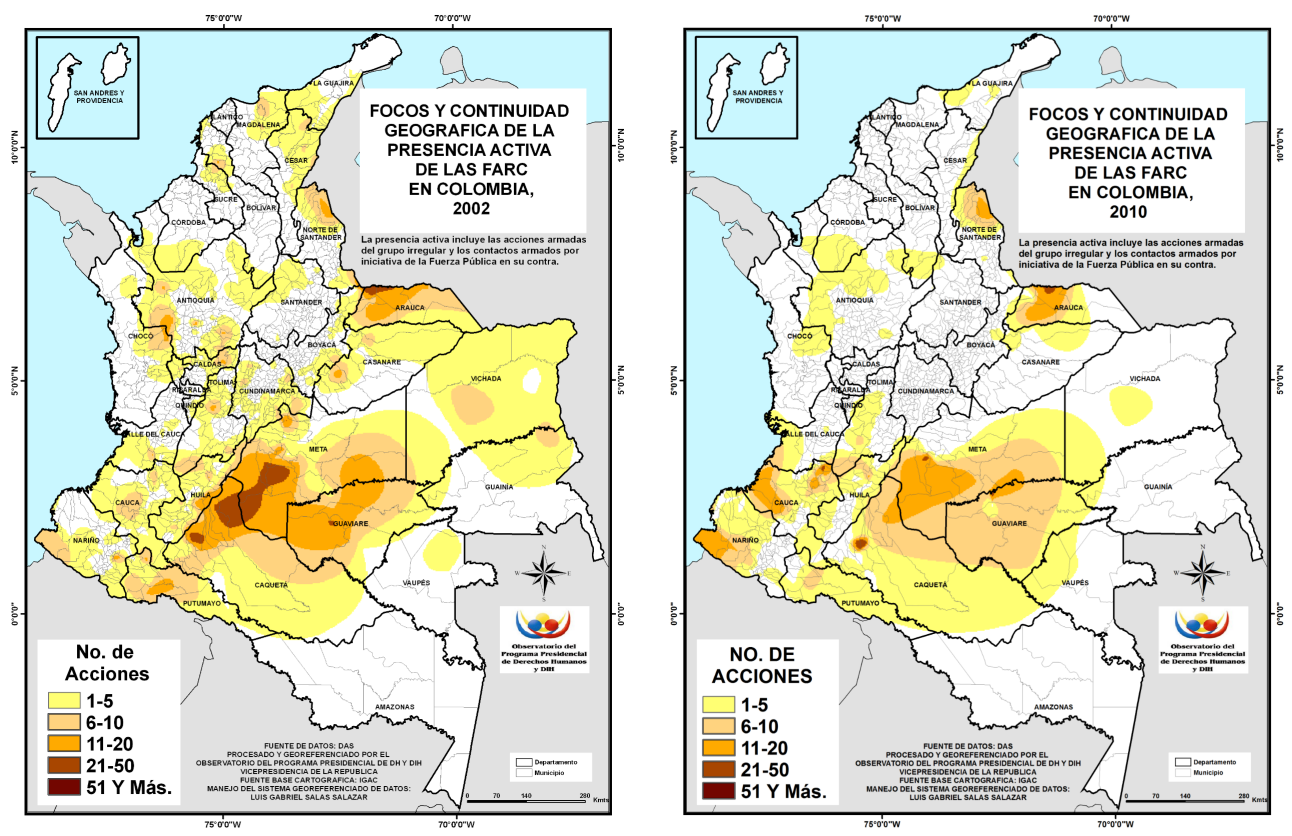

Fuente: ODHDIH (s.f.).

En lo que respecta a Alberto Fujimori, éste llega a la presidencia en 1990, confiriendo continuidad a la política de inteligencia y contrainsurgencia que había iniciado, a finales de los ochenta, su predecesor, el aprista Alan García. No obstante, se flexibiliza mucho el marco jurídico en el que se inscribe el conflicto armado y se permite a las Fuerzas Militares que dispongan de mayor autonomía y discrecionalidad, especialmente, gracias al Decreto 171 de 1990. Una controvertida norma por la cual se protegían bajo fuero militar las acciones comprendidas en zonas de combate y recuperación. 
A lo planteado se unía la optimización de recursos en materia de inteligencia y lucha contrainsurgente, que permite que entre 1990 y 1991 se suceda la detención del $80 \%$ de los responsables senderistas de la propaganda en Lima y que el Grupo Especial de Inteligencia y la DIRCOTE desmantelen la mayor parte de las estructuras urbanas del SL. Ello, en buena medida, porque en los viejos enclaves del corredor andino, Sendero había sido fuertemente golpeado en su estructura de base por la alianza alimentada por Ejército, Marina y comités campesinos de autodefensa (Jiménez, 2000).

El 12 de septiembre de 1992 en el barrio limeño de Surco es detenido Abimael Guzmán junto a otros destacados nombres de la comandancia senderista, como su mujer y número dos de la estructura, Elena Iparraguirre, y Laura Zambrano o María Pantoja, pertenecientes a la dirigencia del PCP-SL. Ese golpe, asestado a la cabeza de la estructura armada, convierte a Sendero Luminoso en un grupo acéfalo, incapaz de reacomodarse, en tanto y en cuanto, y a diferencia de las FARC-EP, el liderazgo de la organización siempre había quedado reducido a una suerte de cultivo mesiánico en torno a la figura del conocido vulgarmente como "Camarada Gonzalo".

Figura 4. Área actual de influencia del post-senderismo

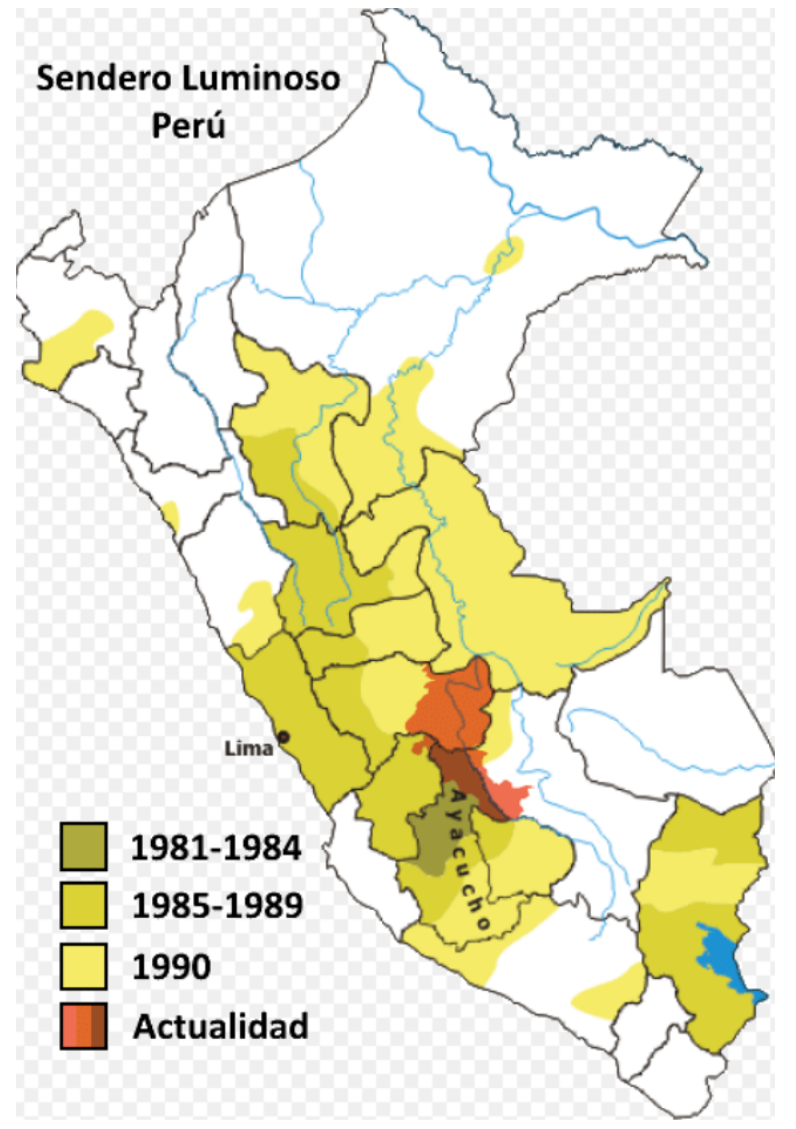

Fuente: Díaz (2015a, p.128). 
De este modo, la intensificación y la casi derrota que experimenta Sendero hacia mediados de los 1990 le lleva a reubicarse territorialmente en dos escenarios periféricos, de vieja presencia, y en donde el cultivo cocalero y el apoyo de las bases campesinas, unido a una difícil accesibilidad para las Fuerzas Militar, ofrece la única válvula de escape para un grupo que en la actualidad no supera el medio millar de integrantes y que difícilmente puede ser asociado a las siglas del Sendero de los años 1990. Se trata de los enclaves del Valle del Alto Huallaga (VAH) y el Valle de los Ríos Apurímac, Ene y Mantaro (VRAEM), que a su vez han sido los dos principales escenarios cocaleros de Perú durante mucho tiempo (UNODC, 2012).

$\mathrm{Y}$ es que, en realidad, el proceso de decadencia del PCP-SL es casi inmediato. Su número de acciones contra la Fuerza Pública pasa de los 338 casos de 1989 a los 130 en 1993. Del mismo modo, experimenta un intenso proceso de merma en el número de efectivos, siendo dados de baja más de 5.000 entre 1989 y 1992, lo cual contrasta con los 919 contabilizados entre 1993 y 1996 (Lynch, 1999: 164). Incluso si bien la detención de "Feliciano" en 1999, que era el último hombre de la dirección del PCP-SL, ya implica para la mayoría de los expertos el fin de la organización. La caída de su último dirigente, "Artemio", en 2012, difícilmente permite entender que el grupúsculo que aún hoy enarbola la bandera del maoísmo y de la lucha armada en Perú sea entendida como continuación alguna de Sendero Luminoso.

Lo que quedaría de este grupo serían algo más de 300 integrantes que se centran en el VRAEM y que son comandados por la familia Quispe Palomino. Un clan mermado en los últimos años, que se erige defensor a ultranza de la necesidad de proseguir con la lucha armada en lo retórico, aunque en lo práctico colaboran con pequeños cárteles y cultivadores de coca desde una posición y una capacidad de combate que, en el mejor de los casos, apenas ha permitido contabilizar en el año 2015 un total de 13 acciones armadas (Díaz, 2015b). En la actualidad se autodenomina como Militarizado Partido Comunista del Perú (MPCP) y no reconoce a la figura de Abimael Guzmán.

\section{Conclusiones}

Llegados a este punto, es posible observar de qué modo los procesos de aparición, evolución, auge y decadencia experimentados por las dos guerrillas andinas más poderosas del siglo XX es profundamente similar. En ambas, la distancia a los centros decisorios del país y la profunda violencia estructural alimentó la opción de la lucha armada, de acuerdo con los numerosos enfoques y aportaciones teóricas que se presentaron en la revisión bibliográfica con la que iniciaba este trabajo.

De otro lado, la acumulación de fuerzas, la diversificación de fuentes de financiación, unido a la capacidad movilizadora y la debilidad institucional del Estado ofrecen una ventana de oportunidad política que en ambos casos es evidente. No obstante, la dimensión militar del Estado, impulsada sobre todo bajo las presidencias de Álvaro Uribe y Alberto Fujimori trunca las expectativas y el sueño de la revolución social que pregonaban desde idearios diferentes las FARC-EP y PCPSL. 
En cualquier caso, ambos grupos armados fueron expulsados nuevamente hacia las periferias que los originaron, haciendo que los conceptos de inaccesibilidad, pero también de recursos y fuentes de financiación ilícita, ofrezcan una explicación a la supervivencia experimentada tras el paso de las décadas. Esto, en tanto que la condición periférica, mayormente fronteriza, cocalera, y alejada de los centros influyentes del país ofrece ventajas competitivas tanto en la acumulación de recursos como en la respuesta frente a los operativos militares que son dirigidos desde el Estado.

Sea como fuere, en el caso del PCP-SL sí que es posible encontrar que su actual condición, a la vez que periférica, resulta notablemente marginal, en la medida en que su capacidad organizativa y de respuesta es muy reducida. Sus apenas 300 integrantes, cada vez más debilitados por la acción del Estado, pero también por la rivalidad de otros grupúsculos que se disputan la presencia y control cocalero en el VRAEM, dan buena cuenta de una situación precaria. El resto de Sendero Luminoso fue o bien eliminado, o bien desarmado y en buena parte juzgado a más de veinte años de cárcel, con la excepción de sus dirigentes, condenados a cadena perpetua. Esto implica una derrota estratégica que en buena medida es igualmente una derrota militar, y que desemboca, por ello, en un discurso político que hoy en día genera el rechazo de la totalidad del arco político partidista y también del espacio mediático peruano.

Realidad diferente experimentaron las FARC-EP, tal vez porque la búsqueda de la centralidad, a diferencia de lo sucedido con Sendero, no se hizo a costa de sacrificar la retaguardia periférica, de manera que el retorno a la condición fronteriza ni mucho menos resultó tan traumático como el de su vecino peruano. Tampoco la estructura quedó desarticulada como en el caso del grupo armado peruano, de modo que la derrota estratégica no se tradujo, per se, en derrota militar. Las FARCEP, en su peor momento de 2010, aún eran 8.500 efectivos, y en las elites de la guerrilla como en las del Gobierno, con la llegada de Juan Manuel Santos en 2010, se compartía el halo de la esperanza de negociar un proceso de intercambios cooperativos con miras a superar la violencia política, de una forma que, en Perú, por la simple detención de su cúpula dirigente, resultaba inviable.

El resultado, nada baladí, ha permitido desmovilizar a más de 7.000 exintegrantes de las FARC-EP y abrir un espacio de participación y cambio político en Colombia, cuyo éxito dependerá, en buena medida, del nivel de compromiso y respaldo que otorgue el nuevo presidente uribista, Iván Duque.

\section{Referencias}

Aghedo, I., y Osumah, O. (2015). Insurgency in Nigeria: A Comparative Study of Niger Delta and Boko Haram Uprisings. Journal of Asian and African Studies, 50(2), 208222.

Aguilera, M. (2010). Las FARC: La guerrilla campesina 1949-2010. Bogotá: Arfo.

Aguilera, M. (2014). Guerrilla y población civil. Trayectoria de las FARC, 1949-2013. Bogotá: Centro Nacional de Memoria Histórica. 
Azcona, J. M., y Re, M. (2015). Guerrilleros, terroristas y revolucionarios (1959-1988). Identidad marxista y violencia política en ETA, Brigadas Rojas, Tupamaros y Montoneros. Pamplona: Aranzadi.

Basedau, M., y Pierskalla, J. (2013). How Ethnicity Conditions the Effect of Oil and Gas on Civil Conflict: A Spatial Analysis of Africa from 1990 to 2010. Political Geography, 38(1), 1-11.

Bates, R. (2008). State failure. Annual Review of Political Science, 11(1), 1-12.

Bejarano, A. M., y Pizarro, E. (2003). Colombia: The Partial Collapse of the State and the Emergence of Aspiring State-Makers. En P. Kingston e I. Spears (Eds.), States Within States: Incipient Politial Entitites in the Post-Cold War Era (pp. 99-118). Nueva York: Pallgrave McMillan.

Bollen, K., y Jackman, R. (1995). Income Inequality and Democratization Revisited: Comment on Muller. American Sociological Review, 60(6), 983-989.

Bracanti, D. (2006). Decentralization: Fueling the Fire or Dampening the Flames of Ethnic Conflict and Secessionism? International Organization, 60(3), 651-685.

Buhaug, H., y Rød, J. (2006). Local Determinants of Africa Civil Wars, 19702001. Political Geography, 25(3), 315-335.

Bushnell, D. (2012). Colombia. Una nación a pesar de sí misma. Bogotá: Planeta.

Cairo, H., Oslender, U., Piazzini Suárez, C. E., Ríos, J., Koopman, S., Montoya Arango, V., ... Zambrano Quintero, L. (2018). "Territorial Peace": The Emergence of a Concept in Colombia's Peace Negotiations. Geopolitics, 23(2), 464-488.

Caïs, J. (1997). Metodología del análisis comparativo. Madrid: Centro de Investigaciones Sociológicas.

Collier, P., y Hoeffler, A. (2004). Greed and grievance in civil war. Oxford Economic Papers, 56(4), 563-595.

CVR (Comisión de la Verdad y Reconciliación). (2003). Informe Final de la Comisión de la Verdad y Reconciliación en el Perú. Lima: CVR.

Degregori, C. I. (1990). El surgimiento de Sendero Luminoso en Ayacucho, 1969-1979. Lima: IEP.

Degregori, C. I. (2011). Qué dificil es ser Dios: el Partido Comunista del Perú - Sendero Luminoso y el conflicto armado interno en el Perú: 1980-1999. Lima: IEP.

Degregori, C. I. (2015). Jamás tan cerca arremetió lo lejos. Lima: IEP.

Díaz, F. (2015a). El neo-senderismo y el tráfico de drogas ilícitas en Perú. Estudios de seguridad y defensa, (5), 123-145.

Diaz, F. (2015b). El Perú y sus múltiples Sendero Luminoso. Relaciones Internacionales, 24(49), 51-75.

Duncan, G. (2006). Los señores de la guerra. Bogotá: Planeta.

Echandía, C. (1999). Geografía del conflicto armado y las manifestaciones de la violencia en Colombia. Bogotá: Universidad de Los Andes.

Echandía, C. (2006). Dos décadas de escalamiento del conflicto armado en Colombia 1986-2006. Bogotá: Universidad Externado.

Echandía, C. (2013). Auge y declive del ELN. Análisis de la evolución militar y territorial de cara a la negociación. Informes de la Fundación Ideas para la Paz, (21). Recuperado de http://cdn.ideaspaz.org/media/website/document/529debc8a48fa.pdf

Echandía, C., y Cabrera, I. (2018). Madurez para la paz. Bogotá: Universidad Externado de Colombia. 
Forø, A., y Buhaug, H. (2015). Insurgency and Inaccessibility. International Studies Review, 17(1), 6-25.

González, J., y Maldonado, R. (2017) Mujeres guerrilleras: la participación de las mujeres en las FARC y el PCP-SL: los casos de Colombia y Perú. Université Le Havre Normandie. Recuperado de https://gric.univ-lehavre.fr/IMG/pdf/gonzalez_maldonado-3.pdf

González-Pérez, M. (2006). Guerrilleras in Latin America: Domestic and International Role. Journal of Peace Research, 43(3), 313-329.

Gorriti, G. (1999). Sendero. Historia de la guerra milenaria en el Perú. Lima: Planeta.

Gott, R. (2008 [1970]). Guerrilla Movements in Latin America. Londres: Seagull Books.

Guevara, E. Che. (2006 [1960]). La guerra de guerrillas. Bogotá: Ocean Sur.

Gutaj, P., y Al, S. (2017). Statehood and the political dynamics of insurgency: KLA and PKK in comparative perspective. Journal of Balkan and Near Eastern Studies, 19(2), 91-104.

Harto, F. (1991). Los procesos de paz en América Central (1979-1991). Tesis de Doctorado en Ciencia Política, Universidad Complutense de Madrid, Madrid.

Hegre, H., Ostby, G., y Raleigh, C. (2009). Poverty and Civil War Events: A Disaggregated Study of Liberia. Journal of Conflict Resolution, 53(4), 598-623.

Horowitz, D. (1985). Ethnic Groups in Conflict. Berkeley, CA: California University Press.

Jiménez, B. (2000). Inicio, desarrollo y ocaso del terrorismo en el Perú: El abc de Sendero Luminoso y el MRTA ampliado y comentado. Lima: Ediciones 2000.

Kaldor, M. (1999). News and Olds Wars: Organized Violence in a Global Era. Londres: Polity Press.

Kalyvas, S. (2006). The Logic of Violence in Civil War. Cambridge: Cambridge University Press.

Kent, R. (1993). Geographical dimensions of the Shining Path insurgency in Peru. Geographical Review, 83(4), 441-454.

Kernaghan, R. (2009). Coca's Gone: Of Might and Right in the Huallaga Post-Boom. Stanford, CA: Stanford University Press.

Krujit, D., Rey, E., y Martín, A. (2020). Latin American Guerrilla Movements. Londres: Reoutledge.

La Serna, M. (2012). The Corner of the Living. Ayacucho on the Eve of the Shining Path Insurgency. Chapel Hill, NC: The University of North Carolina Press.

Letts, R. (1981). La izquierda peruana. Lima: Mosca Azul Editores.

Linke, A., y O'Loughlin, J. (2015). Reconceptualizing, Measuring, and Evaluating Distance and Context in the Study of Conflicts: Using Survey Data from the North Caucasus of Russia. International Studies Review, 17(1), 107-125.

Linke, A., Witmer, F., y O'Loughlin, J. (2012). Space-Time. Granger Analisys of the War in Iraq: A Study of Coalition and Insurgent Action-Reaction. International Interactions, 4(38), 402-425.

Linz, J. J. (1986). La quiebra de las democracias. Madrid: Alianza.

Lynch, N. (1999). Una tragedia sin héroes. La derrota de los partidos y el origen de los independientes. Perú 1980-1992. Lima: Universidad Nacional de San Marcos.

Martí, S., y Figueroa, C. (2006). La izquierda revolucionaria en Centroamérica. Madrid: La Catarata.

Maucerí, P. (2001). Estado, Elite y Contrainsurgencia: una comparación preliminar entre Colombia y Perú. Colombia Internacional, (52), 44-64. 
McDoom, O. (2014). Predicting Violence within Genocide: A Model of Elite Competition and Ethnic Segregation from Rwanda. Political Geography, 42(1), 34-45.

Medellín, P., y Rangel, A. (2010). Política de Seguridad Democrática. Bogotá: Norma.

MINDEFENSA (Ministerio de Defensa Nacional). (20o1). Logros de la Política de Consolidación de la Seguridad Democrática. Bogotá.

Muller, E. N., y Seligson, M. (1987). Inequality and Insurgencies. The American Political Science Review, 81(2), 425-452.

Muller, E. N., Seligson, M. A., Der Fu, H., y Midlarsky, M. I. (1989). Land Inequality and Political Violence. The American Political Science Review, 83(2), 577-596.

O'Loughlin, J. (2012). Climate Variability and Conflict Risk in East Africa, 19902009. Proceedings of the National Academy of Sciences of the United States of America, 45(109), 18344-18349.

ODHDIH (Observatorio de Derechos Humanos y Derecho Internacional Humanitario). (s.f.). Síntesis de la violencia y la confrontación armada en Colombia, 1998- 2012 y 2015. Bogotá: Vicepresidencia de la República.

Otero, D. (2010). El papel de los Estados Unidos en el conflicto armado colombiano. Bogotá: Aurora.

Pécaut, D. (2006). Crónica de cuatro décadas de política colombiana. Bogotá: Norma.

Pécaut, D. (2008). Las FARC, ¿una guerrilla sin fin o sin fines? Bogotá: Norma.

Pinta, P. (2015). El cese de la lucha armada. Un estudio sobre la supervivencia y la desactivación de las organizaciones insurgentes en América Latina (1970-2000). Tesis de Doctorado en Ciencia Política, Universidad Complutense de Madrid, Madrid.

Pizarro, E. (2011). Las FARC (1949-2011). De guerrilla campesina a máquina de guerra. Bogotá: Norma.

Portocarrero, G., y Oliart, P. (1989). El Perú desde la escuela. Lima: Instituto de Apoyo Agrario.

Raleigh, C., y Hegre, H. (2009). Population Size, Concentration and Civil War: A Geographically Dissagregated Analysis. Polítical Geography, 28(4), 224-238.

Rey, E. (2008). Guerrilla o terrorismo. El debate en torno a la caracterización de algunas organizaciones revolucionarias a partir del caso de La Familia. IX Congreso Centroamericano de Historia, Costa Rica.

Rey, E., y Martín Álvarez, A. (2016). Violencia y acceso al poder en América Latina: Uruguay y El Salvador. Revista CIDOB d'Afers Internacionals, (112), 173-195.

Ríos, J. (2016a). La periferialización del conflicto armado colombiano, 2002-2014. Geopolítica(s). Revista de Estudios sobre Espacio y Poder, 7(2), 251-275.

Ríos, J. (2016b). La narcotización del activismo guerrillero de las FARC y el ELN, 19982012. Revista UNISCI, (41), 205-234.

Ríos, J. (2017a). Breve historia del conflicto armado en Colombia. Madrid: La Catarata.

Ríos, J. (2017b). Determinantes geográfico-políticos de la acción violenta guerrillera: un análisis de la concurrencia regional de guerrillas y paramilitares en el conflicto colombiano. Revista Española de Ciencia Política, (44), 121-149

Ríos, J. (2018). Sendero Luminoso: una apología de la violencia. Revista de Cultura de $\mathrm{Paz},(2), 277-294$.

Ríos, J. (2019). "Narratives about Political Violence and Terrorism in Peru”. Latin American Perspectives, 46(5), 44-58.

Ríos, J., y Azcona, J. M. (2019). Historia de las guerrillas en América Latina. Madrid: La Catarata. 
Ríos, J., y García de las Heras, M. (2019). Experiencias sobre el terrorismo de Estado en Perú (1980-2000). Revista Universitaria de Historia Militar, 8(17), 71-96.

Ríos, J., y Sánchez, M. (2018). Breve historia de Sendero Luminoso. Lima: Revuelta Editores.

Ríos, J., y Zapata, J. (2019). "Democratic Security Policy in Colombia: Approaches to an enemy-centric counterinsurgency model”. Revista de Humanidades, (36), 129-154.

Roncagliolo, S. (2007). La cuarta espada: la historia de Abimael Guzmán y Sendero Luminoso. Madrid: Debate.

Ronderos, T. (2014). Guerras recicladas: Una historia periodística del paramilitarismo en Colombia. Bogotá: Aguilar.

Rotberg, R. (2004). When States Fail: Causes and Consequences. Princeton: Princeton University Press.

Rouquie, A. (1994). Guerras y paz en América Central. México D.F.: Fondo de Cultura Económica.

Salas, L. (2010). Corredores y territorios del conflicto armado colombiano: una prioridad en la geopolítica de los actores armados. Perspectiva Geográfica, (15), 9-36.

Salas, L. (2015). Lógicas territoriales y relaciones de poder en el espacio de los actores armados: un aporte desde la geografía política al estudio de la violencia y el conflicto armado en Colombia, 1990-2012. Cuadernos de Geografía, 24(1), 157-172.

Salas, L., Wolf, J., y Camelo, F. (2018). Dinámicas territoriales de la violencia y del conflicto armado antes y después del Acuerdo de Paz con las FARC. Bogotá: Instituto Alemán para la Paz - CAPAZ.

Saleyhan, I. (2009). Rebels without Borders: State Boundaries, Transnational Opposition and Civil Conflict. Nueva York: Cornell University Press.

Sánchez, G. (2009 [1987]) Colombia: violencia y democracia. Comisión de Estudios para la Violencia. Bogotá: La Carreta.

Sánchez, M.. (2015). El horror olvidado. Memoria e historia de la violencia política en Ayacucho (1980-2000). Barcelona. Universidad Autónoma de Barcelona.

Schutte, S. (2015). Geography, Outcome and Casualties: A Unified Model of Insurgency. Journal of Conflict Resolution, 59(6), 1101-1128.

Snyder, R. (2006). Does lootable wealth breed disorder? Comparative Political Studies, 8(39), 943-968.

South, A., y Joll, C. (2016). From Rebels to Rulers: The Challenges of Transition for Nonstate Armed Groups in Mindanao and Myanmar. Critical Asian Studies, 48(2), 168-192.

Taylor, L. (2017). Sendero Luminoso in the New Millennium: Comrades, Cocaine and Counter-Insurgency on the Peruvian Frontier. Journal of Agrarian Change, 17(1), 106121.

UNODC (Oficina de las Naciones Unidas contra la Droga y el Delito). (2012). Perú. Monitoreo de Cultivos de Coca, 2011. Viena: Oficina de las Naciones Unidas contra la Droga y el Delito.

Valenzuela, M. (2019). Cárcel dominio. Una etnografía sobre los senderistas presos en el establecimiento penitenciario Miguel Castro. Lima: Revuelta Editores.

Wickham-Crowley, T. (1991). Guerrillas and Revolution in Latin American. Princeton: Princeton University Press.

Wills, M. E. (2003). Peru`s Failed Search for Political Stability (1968-2000). Crisis State Programme, (1), 1-38. 